\title{
Phytochemical and Biological Investigation of Curcuma amada Leaves
}

\author{
Md. Sakhawat Hossain ${ }^{1,3}$, Md. Mostafizur Rahaman², Md. Atikur Rahman², \\ J alal Uddin ${ }^{2}$ and Firoj Ahmed ${ }^{3}$
}

${ }^{1}$ Department of Pharmacy, Daffodil International University, Daffodil Tower, Sukrabad, Dhaka-1207

${ }^{2}$ Department of Pharmacy, World University of Bangladesh, 151/8, Green Road, Dhaka-1208

${ }^{3}$ Department of Pharmaceutical Chemistry, Faculty of Pharmacy, University of Dhaka

Dhaka-1000, Bangladesh

(Received: July 21, 2019; Accepted: February 24, 2020; Published (web): March 4, 2020)

\begin{abstract}
Methanolic extract of Curcuma amada leaves was investigated for isolation of secondary metabolites by successive chromatographic separation (VLC, column chromatography and TLC) which yielded several purified compounds. Among them the structures of $\beta$-sitosterol and stigmasterol were determined by analysis of high resolution ${ }^{1} \mathrm{H}$ NMR spectroscopic data and co-TLC with authentic samples. The crude methanolic extract of $C$. amada leaves and its different fractionates i.e. petroleum ether (PESF), chloroform (CSF) and aqueous (AQSF) soluble fractions were evaluated for antibacterial, antioxidant, cytotoxic and thrombolytic activities. In antibacterial screening, the CSF exhibited the highest inhibition against bacterial growth having zone of inhibition $12 \mathrm{~mm}$ compared to the standard kanamycin where the zone of inhibition was observed at $18 \mathrm{~mm}$ against gram negative Vibrio mimicus. Significant free radical scavenging activity was also exhibited by CSF with the $\mathrm{IC}_{50}$ value of 103.09 $\mu \mathrm{g} / \mathrm{ml}$ as compared to tert-butyl-1-hydroxytoluene (BHT) having IC $_{50} 31.88 \mu \mathrm{g} / \mathrm{ml}$. In cytotoxicity study, the crude extract showed significant lethality towards brine shrimp having with the $\mathrm{LC}_{50}$ value of $6.540 \mu \mathrm{g} / \mathrm{ml}$ as compared to the standard vincristine sulfate $(0.451 \mu \mathrm{g} / \mathrm{ml})$. In the study for thrombolytic property, different extracts of $C$. amada exhibited clot lysis ranging from 17.24 to $43.55 \%$ as compared to standard streptokinase ( $93.75 \%)$.
\end{abstract}

Key words: Curcuma amada, Sitosterol, Stigmasterol, Antimicrobial, Antioxidant, Thrombolytic activity.

\section{INTRODUCTION}

Curcuma amada, also known as mango ginger (Amada), is indigenous to tropical region especially in India, Thailand, China, Malaysia, Indonesia, Northern Australia and Bangladesh. ${ }^{1}$ The whole plant is used in indigenous system of medicine as a potential medicinal agent. Curcuma (Cúr-cu-ma) is a genus of about 80 accepted species in the family Zingiberaceae that contains such species as turmeric and mango-ginger. Mango-ginger is botanically related to neither mango nor ginger. It is a unique spice having morphological resemblance with ginger (Zingiber officinale) but imparts a raw mango (Mangifera indica) flavor. Various types of chemical

Correspondence to: Firoj Ahmed

Email: firoj72@yahoo.com

Dhaka Univ. J. Pharm. Sci. 19(1): 9-13, 2020 (June)

DOI: https://doi.org/10.3329/dujps.v19i1.47813 constituents have been isolated from mango ginger like curcuminoids, terpenoids, volatile constituents, free phenolic acids etc. ${ }^{2}$

The biological activities of mango ginger include antioxidant, antibacterial, antifungal, antiinflammatory, platelet aggregation inhibitory, and cytotoxic activities. ${ }^{3}$ The objective of the present work was to isolate chemical constituents followed by their biological evaluation.

\section{MATERIALS AND METHODS}

Leaves of $C$. amada were collected from the medicinal plant village, Natore, Bangladesh in 2010 and authentication of the plant sample has been confirmed by Mr. Mostafijur Rahman, Assistant Professor, Department of Botany, University of Rajshahi. 
Extraction and isolation. About $800 \mathrm{gm}$ of powdered leaves were taken in a clean flask and methanol was added for cold extraction process. The whole mixture was filtered through cotton and the solvent was evaporated by using a rotary evaporator. The weight of the crude extract was $32.01 \mathrm{gm}$. About $21.05 \mathrm{gm}$ of extract was fractionated by vacuum liquid chromatographic (VLC) technique using silica gel and dichloromethane, ethyl acetate and finally methanol in increasing order of polarities. Different fractions were collected in beakers according to the TLC analysis designated as $1 \mathrm{~A}, 1 \mathrm{~B}, 1 \mathrm{C}, 1 \mathrm{D}, 1 \mathrm{E}, 1 \mathrm{~F}$ etc. One of the fractions formed crystals which were then recrystallized to give compound 1 (COMP-1). VLC fraction 1D was subjected to silica gel column chromatography with various solvent systems. Numerous fractions were collected which were denoted as 4A, 4B, 4C, 4D, 4E, 4F, 4G, 4H etc. Then $4 \mathrm{E}$ fraction showed crystals which were then recrystallized and washed by methanol. The residue left in the bottom of the test tube was transferred to a vial. By TLC analysis a single band of pink color was found after spraying with conc. sulfuric acid. This compound was termed as compound 2 (COMP-2).

Identification by Nuclear Magnetic Resonance Spectroscopy. The ${ }^{1} \mathrm{H}$ NMR spectra was acquired on a Brucker $(400 \mathrm{MHz})$ instrument in $\mathrm{CDCl}_{3}$ from Bangladesh Council of Scientific and Industrial Research (BCSIR) and Wazed Miah Science Research Centre, Jahangirnagar University.

Biological investigations. The methanolic crude extract (ME) was subjected to solvent-solvent partitioning by using the protocol designed by Kupchan $^{4}$ and modified by Van Wagenen et al. ${ }^{5}$ The crude extract of leaves $(10.0 \mathrm{gm})$ was dissolved in $10 \%$ aqueous methanol to make the mother solution which was successively partitioned to give petroleum ether (PESF), chloroform (CSF) and aqueous (AQSF) soluble fractions.

Anti-bacterial activity. The samples were tested for antibacterial activity by the disc diffusion method. ${ }^{7}$ Dried and sterilized filter paper discs $(6 \mathrm{~mm}$ diameter) containing the test samples of known amounts were placed on nutrient agar medium uniformly seeded with the test microorganisms. Standard antibiotic (Kanamycin) discs and blank discs were used as positive and negative control, respectively. The antibacterial activity of the test agent was determined by measuring the diameter of zone of inhibition expressed in millimeter. ${ }^{6,7}$

Antioxidant activity. The antioxidant potential was determined by using DPPH free radical scavenging assay method and compared to that of tert-butyl-1-hydroxytoluene (BHT) ${ }^{8}$ In short, calculated amount of BHT was dissolved in methanol to get a mother solution having a concentration of $1000 \mu \mathrm{g} / \mathrm{ml}$. Then serial dilution was made to get different concentrations from 500.0 to $0.977 \mu \mathrm{g} / \mathrm{ml}$. Calculated amount of petroleum ether, chloroform and aqueous fraction of methanolic extract of $C$. amada were dissolved in methanol to get mother solution having a concentration of $1000 \mu \mathrm{g} / \mathrm{ml}$. Then serial dilution was made to get the concentrations from 500.0 to $0.977 \mu \mathrm{g} / \mathrm{ml}$.

Then $2.0 \mathrm{ml}$ of the methanol solution of the sample (control/extracts) at different concentrations from 500.0 to $0.977 \mu \mathrm{g} / \mathrm{ml}$ were mixed with $3.0 \mathrm{ml}$ of DPPH methanol solution $(20 \mu \mathrm{g} / \mathrm{ml})$. After 30 minutes of reaction period at room temperature in dark place, the absorbance was measured at $517 \mathrm{~nm}$ against methanol as blank by UV spectrophotometer. ${ }^{9}$ Inhibition of free radical DPPH in percent (I \%) was calculated as follows:

$$
(\mathrm{I} \%)=\left(1-\mathrm{A}_{\text {sample }} / \mathrm{A}_{\text {blank }}\right) \times 100
$$

where $A_{\text {blank }}$ is the absorbance of control reaction (containing all reagents except the test material)

Extract concentration providing 50\% inhibition $\left(\mathrm{IC}_{50}\right)$ was calculated from the graph plotted by inhibition percentage against extract concentration.

Cytotoxic activity. Cytotoxic activity of the crude extract and its different fractions were determined by brine shrimp lethality bioassay method as described by Meyer et al. ${ }^{10}$ All the test samples ME, PESF, CSF, AQSF were taken in vials and dissolved in $200 \mu \mathrm{l}$ of dimethyl sulfoxide (DMSO) to get stock solutions. These solution were used to test the lethal effect against the brine shrimp Artemia salina nauplii. 
Thrombolytic activity. The in vitro thrombolytic activity of the test samples of $C$. amada was determined according to the method reported earlier ${ }^{11}$ and percentage of clot lysis was calculated by using the formulae shown below:

$\%$ clot lysis $=($ Weight of the released clot $/$ Weight of clot before lysis) $\times 100$.

\section{RESULTS AND DISCUSSION}

Chemical investigations of $C$. amada. A total of eight compounds were obtained from VLC fractions of crude methanolic extract of the leaves of $C$. amada. Among them two of the compounds COMP-1 and COMP-2 were $\beta$-sitosterol and stigmasterol. Rest of the compounds could not be characterized due to lack of proper information in NMR spectra of impure compounds

Characterization of COMP-1 as $\boldsymbol{\beta}$-sitosterol. $\beta$-sitosterol was obtained as white color needle shaped crystals. It showed violet color on the plate after spraying with conc. sulfuric acid regeant followed by heating at $110^{\circ} \mathrm{C}$ for $5-10$ minutes. ${ }^{1} \mathrm{H}$ NMR spectrum $\left(400 \mathrm{MHz}, \mathrm{CDCl}_{3}\right.$ ) of $\beta$-sitosterol (Figure 1) was almost identical to that recorded for authentic sitosterol. ${ }^{12}$ Co-TLC with a sample of sitosterol previously isolated in our laboratory confirmed its identity as $\beta$-Sitosterol.

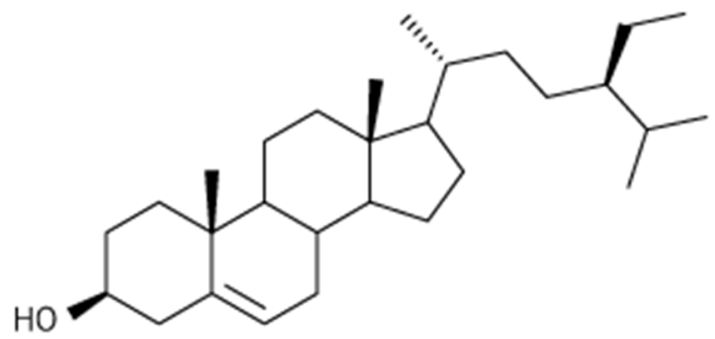

Figure 1. $\beta$-Sitosterol

Characterization of COMP-2 as Stigmasterol. The white needle shaped crystals of compound 2 was soluble in chloroform. It produced violet color on TLC after spraying with conc. sulfuric acid followed by heating at $110^{\circ} \mathrm{C}$ for $5-10$ minutes. The ${ }^{1} \mathrm{H}$ NMR spectrum $\left(400 \mathrm{MHz}, \mathrm{CDCl}_{3}\right.$ ) of stigmasterol (Figure 2) displayed signals characteristic of a steroidal compound. Comparison of the spectrum with that acquired for authentic sample of stigmasterol as well as co-TLC confirmed the identity of that compound 2 as stigmasterol.

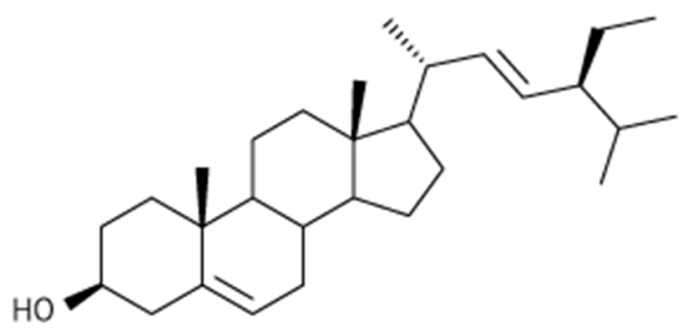

Figure 2. Stigmasterol

Anti-bacterial activity. The chloroform soluble fraction (CSF) exhibited the highest inhibition of bacterial growth having zone of inhibition $7.0 \mathrm{~mm}$ to $12.0 \mathrm{~mm}$. The maximum zone of inhibition produced by CSF was $12.0 \mathrm{~mm}$ against $S$. aureus (gm ve+) and $V$. mimicus (gm ve-). The results of in-vitro microbial screening of leaf of $C$. amada indicated that CSF and MESF possess better antibacterial activity that also support its traditional use. However, AQSF and PESF revealed mild antibacterial activity. These can be further studied to explore potent antibacterial agents. The results are given in table 1.

Anti-oxidant activity. Among all extractives of $C$. amada leaves the chloroform soluble fractionn (CSF) showed moderate anti-oxidant activity with $\mathrm{IC}_{50}$ value of $103.09 \mu \mathrm{g} / \mathrm{ml}$ as compared to standard tert-butyl-1-hydroxytoluene $\quad\left(\mathrm{IC}_{50}=31.88 \mu \mathrm{g} / \mathrm{ml}\right)$. Other fractions (AQSF, PESF and ME) showed weak free radical scavenging activity. The $\mathrm{IC}_{50}$ value of other fractions are shown in table 2.

Cytotoxicity by brine shrimp lethality bioassay. Each of the test samples showed different mortality rates at different concentrations. Plotting of $\log$ of concentration versus percent mortality for all test samples showed an approximate linear correlation. From the graphs, the median lethal concentration $\left(\mathrm{LC}_{50}\right.$, the concentration at which $50 \%$ mortality of brine shrimp nauplii occurred) was determined for the samples. Vincristine sulfate (VS) was used as positive control and the $\mathrm{LC}_{50}$ was found as $0.451 \mu \mathrm{g} / \mathrm{ml}$. The $\mathrm{LC}_{50}$ values of ME, CSF, PESF 
and AQSF were found to be $6.540 \mu \mathrm{g} / \mathrm{ml}, 13.637$ $\mu \mathrm{g} / \mathrm{ml}, 7.134 \mu \mathrm{g} / \mathrm{ml}, 16.66 \mu \mathrm{g} / \mathrm{ml}$ respectively. MESF and PESF showed significant lethality whereas CSF, AQSF are showed moderate activity. In the present bioactivity study the crude extracts, and its different fractions showed positive results indicating that the test samples are biologically active. The results are given in table 3 .

Table 1. Antibacterial activity of C. amada.

\begin{tabular}{|c|c|c|c|c|c|}
\hline Test Bacteria & MESF & PESF & CSF & AQSF & Kanamycin $(30 \mu \mathrm{g} / \mathrm{disc})$ \\
\hline \multicolumn{6}{|c|}{ Gram positive bacteria } \\
\hline Bacillus cereus & 10 & 7 & 7 & 9 & 26 \\
\hline Bacillus subtilis & 8 & - & 7 & - & 27 \\
\hline Staphylococcus aureus & - & 9 & 12 & 8 & 25 \\
\hline Sarcinalutea & - & - & - & 7 & 27 \\
\hline \multicolumn{6}{|c|}{ Gram negative bacteria } \\
\hline Escherichia coli & 10 & 8 & 9 & 8 & 27 \\
\hline Salmonella typhi & 8 & - & 8 & - & 28 \\
\hline Shigella dysenteriae & - & 9 & 7 & - & 27 \\
\hline Vibrio mimicus & - & - & 12 & 7 & 18 \\
\hline Vibrio parahemolyticus & - & 8 & 9 & - & 20 \\
\hline
\end{tabular}

ME: Methanol Extract; PESF: Petroleum ether soluble fraction; AQSF: Aqueous soluble fraction; CSF: Chloroform soluble fraction

Table 2. $\mathrm{IC}_{50}$ values of crude extract and partitionates of leaves of C. amada and BHT.

\begin{tabular}{ll}
\hline Sample & $\mathrm{IC}_{50}(\mu \mathrm{g} / \mathrm{ml})$ \\
\hline $\mathrm{ME}$ & 749.96 \\
$\mathrm{CSF}$ & 103.09 \\
$\mathrm{PESF}$ & 558 \\
$\mathrm{AQSF}$ & 470 \\
BHT $(\mathrm{Std})$ & 31.88 \\
\hline
\end{tabular}

ME: Methanol extract; PESF: Petroleum ether soluble fraction; AQSF: Aqueous soluble fraction; CSF: Chloroform soluble fraction; BHT: tert-butyl-1-hydroxytoluene

Table 3. Cytotoxic activity of different fractions of $C$. amada.

\begin{tabular}{lccc}
\hline $\begin{array}{l}\text { Test } \\
\text { samples }\end{array}$ & Regression line & $\mathrm{R}^{2}$ & $\begin{array}{c}\mathrm{LC}_{50} \\
(\mu \mathrm{g} / \mathrm{ml})\end{array}$ \\
\hline VS & $\mathrm{y}=30.8 \mathrm{x}+60.645$ & 0.973 & 0.451 \\
ME & $\mathrm{y}=37.04 \mathrm{x}+19.79$ & 0.912 & 6.540 \\
CSF & $\mathrm{y}=39.46 \mathrm{x}-5.224$ & 0.983 & 13.637 \\
PESF & $\mathrm{y}=38.05 \mathrm{x}+17.53$ & 0.929 & 7.134 \\
AQSF & $\mathrm{y}=34.42 \mathrm{x}-7.945$ & 0.918 & 16.66 \\
\hline
\end{tabular}

ME: Methanol extract; PESF: Petroleum ether soluble fraction; AQSF: Aqueous soluble fraction; CSF: Chloroform soluble fraction; VS: Vincristine sulfate

Thrombolytic activity. The percentage of weight loss of clot after the application of crude extract of $C$. amada was taken as the indication of thrombolytic activity. The $\%$ of clot lysis by crude methanolic extract of $C$. amada was $43.55 \%$ as compared to standard streptokinase $\left(\mathrm{LC}_{50}=93.75 \%\right)$. The crude methanolic extract of $C$. amada showed significant thrombolytic activity which supports the traditional use of this plant in various diseases. The results are given in table 4.

Table 4. In vitro investigation of thrombolytic activity of $C$. amada leaves.

\begin{tabular}{lc}
\hline Sample & \% of clot lysis leaf part \\
\hline ME & 43.55 \\
CSF & 23.96 \\
PESF & 21.82 \\
AQSF & 17.24 \\
SK & 93.75 \\
\hline
\end{tabular}

ME: Methanol extract; PESF: Petroleum ether soluble fraction; AQSF: Aqueous soluble fraction; CSF: Chloroform soluble fraction; SK: Streptokinase

\section{CONCLUSION}

Two compounds were isolated by successive chromatographic separation and purification of a crude extract of $C$. amada. Various types of test were done to evaluate the biological activities of the leaves of $C$. amada. The chloroform soluble fraction (CSF) exhibited maximum zone of inhibition of $12.0 \mathrm{~mm}$ against $S$. aureus $(\mathrm{gm}+\mathrm{ve})$ and $V$. mimicus (gm ve-). 
Among all extractives of $C$. amada, moderate free radical scavenging activity was given by CSF $\left(\mathrm{IC}_{50}=103.09 \mu \mathrm{g} / \mathrm{ml}\right)$ as compared to the standard BHT $\left(\mathrm{IC}_{50}=31.88 \mu \mathrm{g} / \mathrm{ml}\right)$. The $\mathrm{LC}_{50}$ values of $\mathrm{ME}$ was found to be $6.540 \mu \mathrm{g} / \mathrm{ml}$ as compared to standard vincristine sulfate $(0.451 \mu \mathrm{g} / \mathrm{ml})$. The percentage of clot lysis by ME of C. amada (leaf) was $43.55 \%$ as compared to standard streptokinase (93.75\%) which supports the traditional use of this plant as thrombolytic agent.

So, considering the potential bioactivities, this plant can be further studied to find out its unexplored efficacy and to rationalize its medicinal uses.

\section{ACKNOWLEDGEMENT}

This project was partially supported by the Grant for Advanced Research in Education (GARE), Ministry of Education, Government of the People's Republic of Bangladesh.

\section{REFERENCES}

1. Sasikumar, B. 2005. Genetic resource of Curcuma: diversity, characterization and utilization. Plant Genetic Resource. 3, 230-251.

2. Policegoudra R.S., Aradhya S.M. and Singh L 2011. Mango ginger (Curcuma amada Roxb.): a promising spice for phytochemicals and biological activities. J. Biosci. 34-36, 739-748.

3. Policegoudra RS, Rehna K, Rao LJ and Aradhya SM 2010. Antimicrobial, antioxidant, cytotoxicity and platelet aggregation inhibitory activity of a novel molecule isolated and characterized from mango ginger (Curcuma amada Roxb.) rhizome. J. Biosci. 35, 231-240.
4. Kupchan, S.M. 1970. Recent advances in the chemistry of terpenoid tumor inhibitors. Pure Appl. Chem. 21, 227-246.

5. Van Wagenen, B.C., Larsen, R., Cardellinall, J.H., Randazzo, D., Lidert, Z.C. and Swithenbank, C. 1993. Ulosantoin, a potent insecticide from the sponge Ulosa ruetzleri. J. Org.Chem. 58, 335-337.

6. Ahmed F., Islam M.A. and Rahman M.M., Antibacterial activity of Leonurus sibiricus aerial parts. Fitoterapia. 77, 316-317.

7. Ahmed F., Das P.K., Islam M.A, Rahman K.M., Rahman M.M. and Selim M.S.T., Antibacterial activity of Cordyline terminalis. Kunth. leaves. J. Med. Sci. 3 (5-6), 418-422.

8. Ahmed F., ShahidI.Z., Razzak M.A., Rahman M.M., HoqueT and Rahman M.T., Free radical scavenging activity of some Mangroves available in Bangladesh. Oriental Pharm. Exp. Med. 6, 58-64.

9. Brand-Williams, Cuvelier, W. and Berset, C., 1995. Use of free radical method to evaluate antioxidant activity. Lebensm. Wiss. Technol. 28, 25-30.

10. Meyer, B.N., Ferrigni, N.R., Putnam, J.E., Jacobsen, L.B., Nichols, D.E., and McLaughlin, J.L. 1982. Brine shrimp: a convenient general bioassay for active plant constituents. Planta Med. 45, 31-34.

11. Prasad, S., Kashyap, R.S., Deopujari, J.Y., Purohit, H.J.,Taori, G.M. and Daginawala, H.F. 2007. Effect of Fagonia arabica on in vitro thrombolysis. BMC Complement. Alternat. Med. 7, 36-41.

12. Pateh, U.U., Haruna, A.K., Garba, M., Iliya, I., Suly, I. M., Abubakkar, M.S., and Ambi, A. A. 2009. Isolation of stigmasterol, $\beta$-sitosterol and 2-hydroxyhexadecanoic acid methyl ester from the rhizomes of Stylochiton lancifolius pyer and kotchy (Araceae). Nig. J. Pharm. Sci. 8, $19-25$. 